DE DE GRUYTER OPEN
J oumal of Intercultural Management

Vol. 5, No. 1, March 2013, pp. 5-17

DOI 10.2478/joim-2013-0001

Jerzy Mączyński

Łukasz Sułkowski

Michał Chmielecki

Agnieszka Zajączkowska

Społeczna Akademia Nauk w Łodzi

\title{
Longitudinal Studies on Traits and Behaviors of Polish Managers
}

\begin{abstract}
The main objective of our research was to compare followers evaluation of Polish middle managers in regard to their traits and behaviors, which are essential for leadership effectiveness, in the years of 2008/2009; 2010/2012; 2012 and during 1996/1997 under the GLOBE research project.

As was unexpected, our research results indicate the Polish middle managers under our follow-up study scored significantly lower than their counterparts investigated under the GLOBE study in 1996/1997 on Performance Orientation, Team Orientation, Humane Orientation, Integrity, Visionary and Inspirational Leadership Dimensions, and significantly higher on Autocratic Leadership style.

Our findings point to the conclusion that profound changes in political and socioeconomic systems in Poland, have shown little effects so far on managerial values and subsequent attitudes and behaviors. We postulate that deep changes in peoples' mentality are needed to generate beneficial changes in the societal and organizational values and succeeding attitudes and behaviors.
\end{abstract}

Key-words: middle managers, leadership effectiveness, behaviors.

\section{Introduction}

The main goal of our current research presented in this paper was to compare followers evaluations of Polish middle managers in regard to their traits and behaviors in the years of 2008/2009; 2010/2011; 2012 and evaluations from 
6 J. Mączyński, Ł. Sułkowski, M.Chmielecki, A. Zajączkowska

the part of managers investigated during 1996/1997 under the GLOBE research project.

The Poland of today is facing an immense political and socioeconomic change, and is designing the suitable institutions and legislations that should be advantageous to a democratic system. Therefore we have assumed that there is a good reason to predict that the political and economic transformation in Poland should be beneficial for shaping organizational culture and managerial practices and values.

\section{Method}

The leadership measurements asked followers to assess their superiors according to seven traits that are presented below:

1. Performance Orientation: improvement oriented, excellence oriented, achievement oriented.

2. Team Orientation: group oriented, collaborative, loyal, consultative.

3. Humane Orientation: generous, compassionate.

4. Autocratic Orientation: dictatorial, bossy, elitist.

5. Integrity Leadership Dimension: honest, sincere, just, trustworthy.

6. Visionary Leadership Dimension: foresight, prepared, anticipatory, plans ahead.

7. Inspirational Leadership Dimension: enthusiastic, positive, morale booster, motive arouser.

In generating leadership traits and behaviors, the items were based on several existing leadership theories, as described by House, et al., [1997]. All scales developed in GLOBE study are based on extensive pilot study [see House, et al., 2004]. Questionnaire items developed in GLOBE project were translated from English to Polish, and after that translated back into English language. Back-translation was checked by the GLOBE coordinating team.

\section{Analysis of Research Results}

Research data analyzed in our paper concerning Polish managers investigated during 1996/1997 were drawn from extensive cross-cultural research under the GLOBE project, which was developed to study societal, organizational and leadership traits and behaviors through the use of multiple methods and at multiple levels of analysis [House, et al., 1997 a; b]. In turn research data concerning Polish managers studied in the years of 2008/2009, 2010/2011 and 2012 have been collected partly by the authors of this paper.

In the years of 1996/1997 two hundred seventy seven Polish middle managers completed the „Leader Attribute Questionnaire” developed by GLOBE research project. In the remaining years we have been able to conduct a follow-up study among 342 followers employed by several organizations located in different 
parts of Poland (including Legnica, Świdnica, Wrocław, Łódź, Warszawa). Followers of Polish middle managers, tested in those years, completed identical questionnaires as followers investigated under the GLOBE project.

\section{Performance Orientation}

Under the GLOBE project, performance orientation is defined as the extent to which organization encourages and rewards innovation, setting high standards, challenging goals, and performance improvement.

The differences between compared groups of managers on Performance Orientation are presented in Figure 1.

Figure 1: Differences between Polish managers of 1996/1997, 2008/2009, 2010/2011 and of 2012 on Performance Orientation.

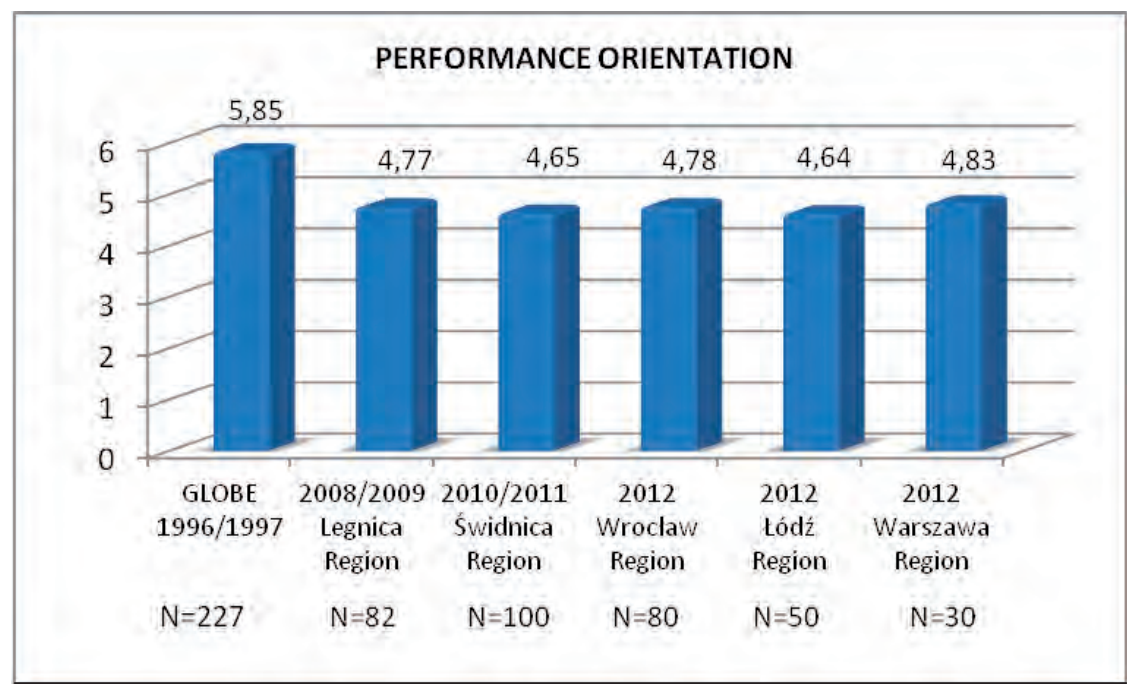

Our research data displayed in Figure 1, indicate that Polish managers investigated in 2008/2009; 2010/2011; 2012 according to their followers demonstrate lower level of Performance Orientation than managers estimated under the GLOBE project in 1996/1997. It may appear that newer generations of Polish managers demonstrate weaker motivation to improve their work performance and develop their potentials.

Based on the GLOBE research results, societies whose members express strong Performance Orientation, value education and learning, accentuate results, set high performance goals, and value taking initiative [House, et al., 2004].

David C. McClelland [1987] introduced the concept of need for achievement, which was defined as a tendency to do better all the time. He noted that 
organizational members with high need for achievement tend to achieve satisfaction from progressive work improvement, prefer to work on tasks with moderate chances of success, assume personal responsibility for their activities, look for frequent feedback, search for knowledge on how to perform work better, and are in general innovative.

GLOBE findings on Performance Orientation practices, proved that performance oriented societies are more economically prosperous. Measures of economic health used by GLOBE, found strong and significant correlation with three scales: „economic prosperity(correlation=.573, p<.001), public support for economic prosperity(correlation=.547, $\mathrm{p}<.001$ ), and societal support for economic prosperity (correlation=.367, p<.05, House, 2004, p.254)".

It is worthwhile to mention, that Hofstede and Bond [1988] proved that "Confucian Dynamism" was significantly correlated with economic growth among 22 nations under study. Their description of "Confucian Dynamism” has a great deal in common with McClelland's need for achievement and GLOBE's Performance Orientation lending support for the argument that societal and organizational practices that encourage achievement orientation are solution to economic and business development and success.

\section{Team Orientation}

Team Orientation is a leadership attribute that emphasizes effective team building, cooperation, loyalty, consultation and implementation of common goals by team members.

Figure 2 presents the data concerning differences between Polish middle managers studied under the GLOBE study and our follow-up investigation.

Figure 2: Differences between Polish managers of 1996/1997, 2008/2009, 2010/2011 and of 2012 on Team Orientation.

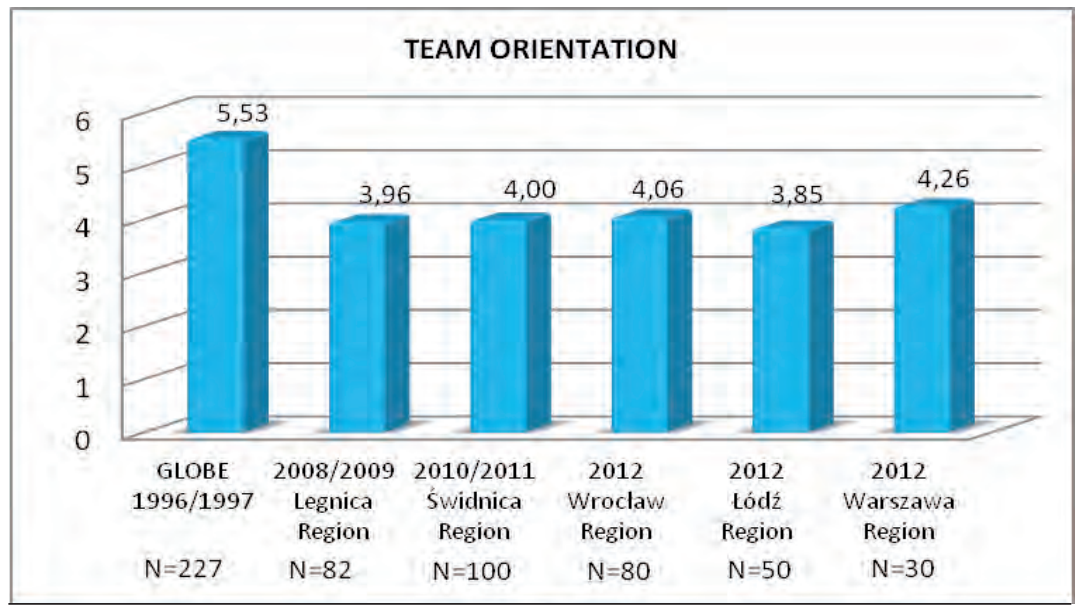


From the results presented in Figure 2, it can be clearly seen that Polish middle managers investigated in the years of 2008/2009; 2010/2011 and 2012, in comparison with managers studied under the GLOBE project, score significantly lower on team orientation. It can be concluded that managers investigated under our follow-up study express lower consideration towards followers interests and views.

In the GLOBE research it has been found that team-oriented leaders tend to emphasize mutual interests rather than differences. Explain the importance of cooperation, between team members for shared organizational goals, as well as individual objectives. Encourage team members to exchange information and elicit additional ideas, and help each other.

Diverse studies provide ample evidence that leader's skills in team-building are highly relevant for strengthening followers identification with the organization's mission and managerial effectiveness [Peters and Austin, 1985; Tichy and Devanna, 1986].

\section{Humane Orientation}

Humane Orientation can be defined as the degree to which society or organization encourage and rewards people for being generous, altruistic, friendly, caring and kind to others.

"Humane Orientation is operationalized as the degree of concern, sensitivity, friendship, tolerance, and support that is extended to others at the societal, organizational, and leadership levels" [House, et al., 2004, p.595].

Figure 3 displays the data related to differences between Polish middle managers investigated under the GLOBE study and our follow-up investigation.

Figure 3: Differences between Polish managers of 1996/1997, 2008/2009, 2010/2011 and 2012 on Humane Orientation.

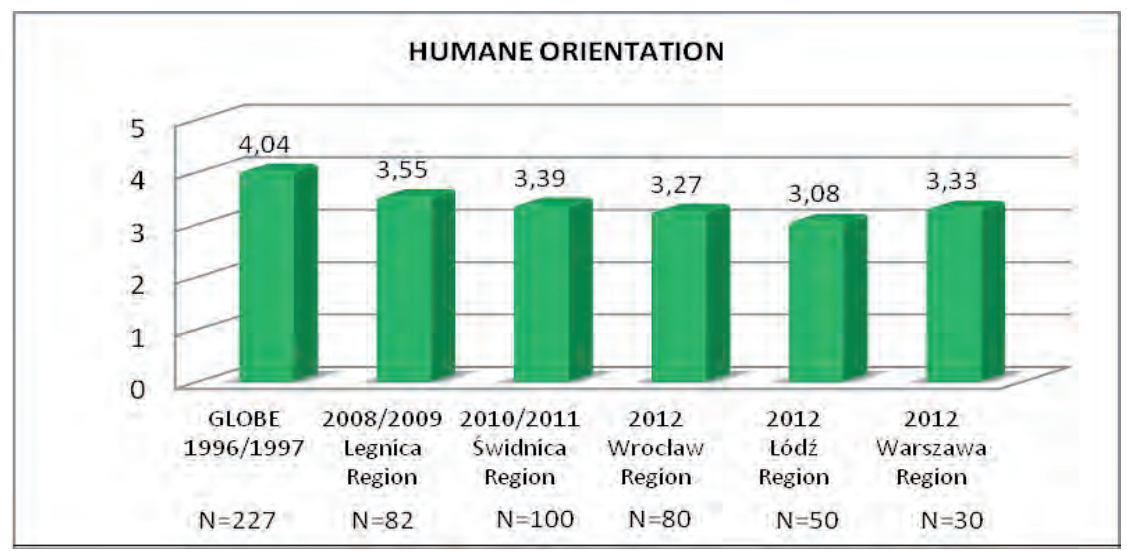


Our research results presented in Figure 3, indicate that Polish managers, from the point of view of their followers, investigated under the follow-up study display lower level of humane orientation than Polish managers studied under the GLOBE project.

As viewed by the GLOBE study, highly humane-oriented behaviors are concerned with expressing care, nurturance, and help to others, while low humane orientation imply encouraging self-interest and lack of consideration to other people. Humane orientation of managers is closely related to the economic, physical, and psychological well-being of their followers.

As revealed by the GLOBE study results, the more an organization value Humane Orientation, the higher the members of that organization rate Participative Leadership style as a desired attribute and the lower they rate Autocratic Leadership behavior as essential factor for being effective [House, et al., 2004; Mączyński, et al., 1994; Mączyński, 2001; 2002].

\section{Autocratic Orientation}

Autocratic leadership attribute, under the GLOBE project is defined as being dictatorial, bossy and making decisions in a command manner.

The differences between analyzed groups of middle Polish managers are shown in Figure 4.

Figure 4: Differences between Polish managers of 1996/1997, 2008/2009, 2010/2011 and 2012 on Autocratic Orientation.

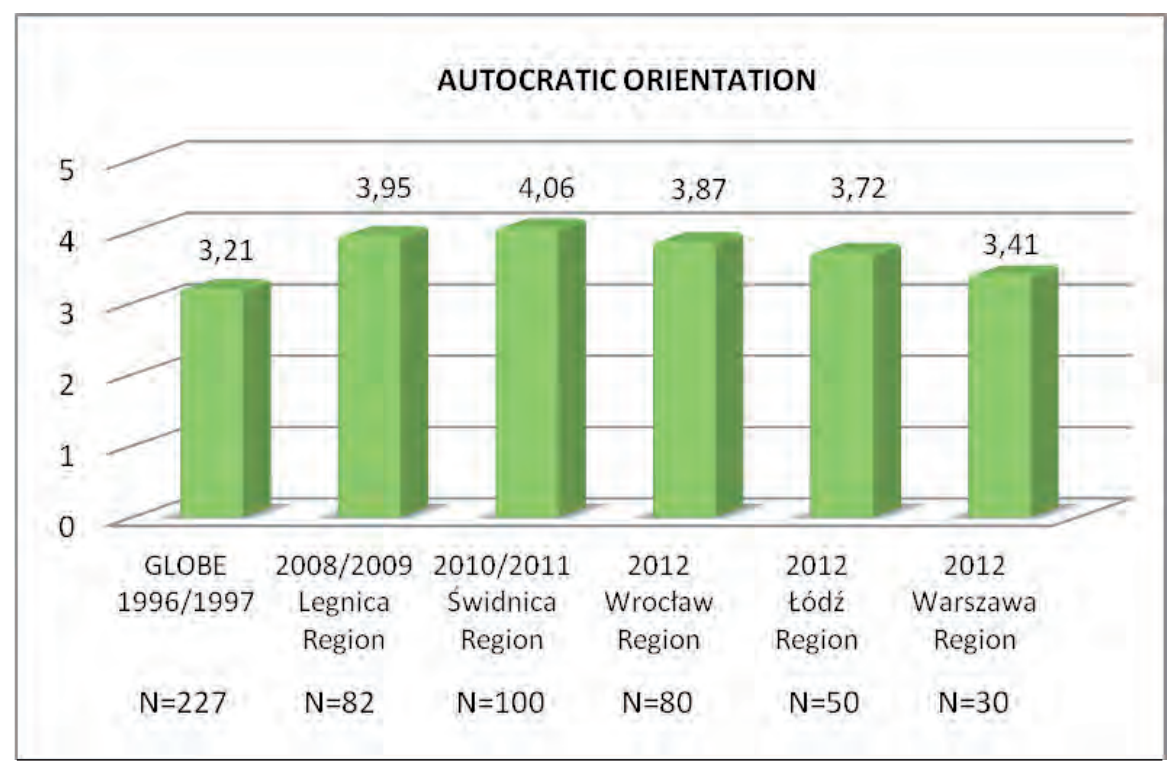


From a comparison of the results presented in Figure 4, it can be easily seen that Polish middle managers investigated under the follow-up study score higher on Autocratic dimension than middle managers investigated in 1996/1997 under the GLOBE project.

It is worthwhile to mention that the GLOBE results revealed that Polish managers were expected to behave more often in a highly autocratic manner than their western counterparts [Szabo, et al., 1997]. Some of the research data from the GLOBE project indicate that Polish managers report that their followers tend not to question their superiors, but instead significantly more often pointed to their superiors as the authority responsible for dealing with on-going work events and making organizational decisions. On the other hand western managers report that followers in a situation where there is disagreement with their superiors express a tendency to question their orders rather than obey them [Szabo, et al., 1997].

It should be noted that the current situation in Poland is vastly different from the circumstances that prevailed under previous system. There is no longer such a strong tendency to apply coercion as a means for obtaining managerial control. As a consequence employees nowadays have much more power and a concurrent expectation that their views will be asked for and will be taking into consideration. In other words, managers should no longer function effectively by applying traditional autocratic leadership style. Polish organizations of today need more participative managerial practices compatible with human resources conception [Mączyński, 1998].

\section{Integrity Leadership Dimension}

Integrity as leadership attribute within the GLOBE project is defined as being trustworthy, just, honest and sincere.

Figure 6 reports the differences between analyzed groups of Polish middle managers on Integrity Leadership Dimension.

From a comparison of our research results displayed in Figure 6, it can be concluded that Polish middle managers investigated under our follow-up study score significantly lower on Integrity Leadership Dimension, than their counterparts studied in 1996/1997 under the GLOBE project.

Leaders with high integrity have insight into the needs, interests, and values of their followers, and are able to arouse strong emotions and identification with organizational goals. High integrity leaders are likely to set an example through their own behavior for followers to stimulate enthusiasm and effort. Through this process such a leaders are able to exert substantial influence on the satisfaction and motivation of their followers. According to Yukl „subordinates are usually more satisfied with a leader who is friendly and helpful, shows trust and respect, and demonstrates concern for their needs and feelings" [Yukl, 1994, p.446]. 
Figure 5: Differences between Polish managers of 1996/1997, 2008/2009, 2010/2011 and 2012 on Integrity Leadership Dimension.

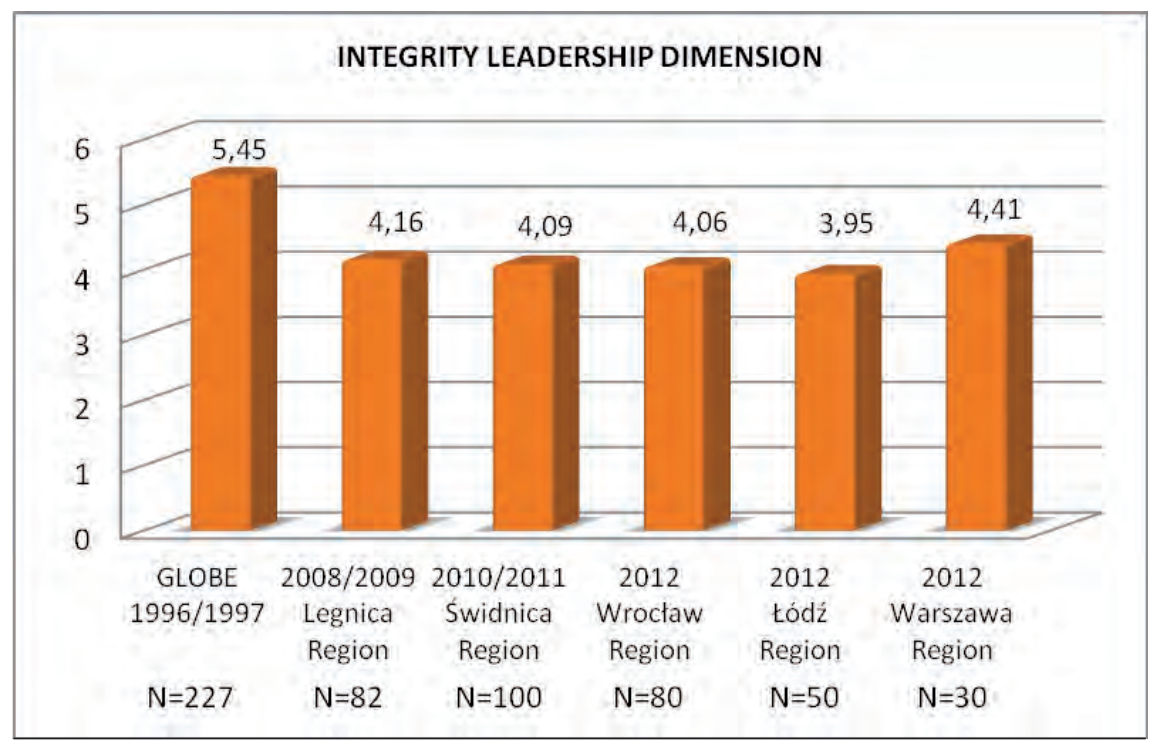

Followers of high integrity leader have a feelings of trust, admiration, respect and loyalty towards the leader, and they are willing to do more than they were expected to do. Followers are more aware of the importance of the goal outcomes, and are willing to devote their own self-interest for the sake of the organization.

\section{Visionary Leadership Dimension}

Under the GLOBE project Visionary Leadership is characterized by the following terms: foresight, anticipatory, prepared, intellectually stimulating, future oriented, inspirational. Cultural future orientation is the degree to which a society or organization encourages and rewards future-oriented behaviors such as planning and delaying gratification.

An important aspect of visionary leadership is envisioning the future, providing long-term direction and articulating it to followers. Thomas and Greenberger[1995] concluded that the ability to create vision is to some extent dependent on future-time perspective characterized by the leader. A leader who is focused on future orientation is willing to direct his energy toward the future.

Figure 6 displays the differences between compared groups of Polish middle managers on Visionary Leadership Dimension. 
Figure 6: Differences between Polish managers of 1996/1997, 2008/2009, 2010/2011 and 2012 on Visionary Leadership Dimension.

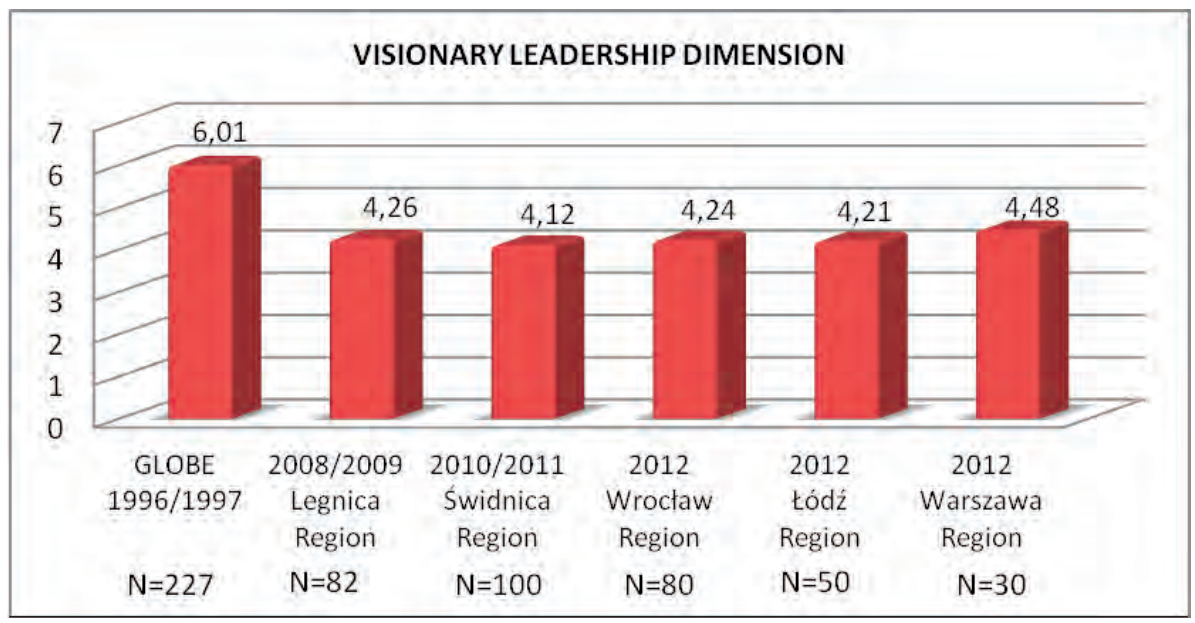

The data presented in Figure 6, show substantial evidence of differences in mean score on Visionary Leadership between compared groups of respondents. Polish middle managers investigated on our follow-up study display significantly lower level of visionary leadership attribute than their counterparts studied in the years of 1996/1997 under the GLOBE project.

GLOBE study discovered that future-oriented practices are positively correlated with societal health and general satisfaction [House, et al., 2004, p.316].

Hofstede and Bond [1988] postulated that "Confucian Dynamism is, in essence, a "dynamic", future oriented mentality”, as opposed to a static oriented mind-set. Hofstede [1991;2000] concluded that a long-term orientation is essential for a high tendency to save while a short-term orientation results in a tendency to enjoy leisure in the present time and emphasize only immediate concerns of the people.

Organizations that value future orientation, reveal a tendency to endorse the effectiveness of Visionary Leadership. Visionary leaders have the ability to inspire and motivate followers to work hard in order to achieve organizational goals.

\section{Inspirational Leadership Dimension}

Under the GLOBE project, Inspirational Leadership reflects the ability to inspire, to motivate, to encourage, to built confidence, and to expect high work performance from the part of followers.

The last Figure(Number 7) displays the differences between compared groups of Polish middle managers on Inspirational Leadership Dimension. 
Figure 7: Differences between Polish middle managers of 1996/1997, 2008/2009, 2010/2011 and 2012 on Inspirational Leadership Dimension.

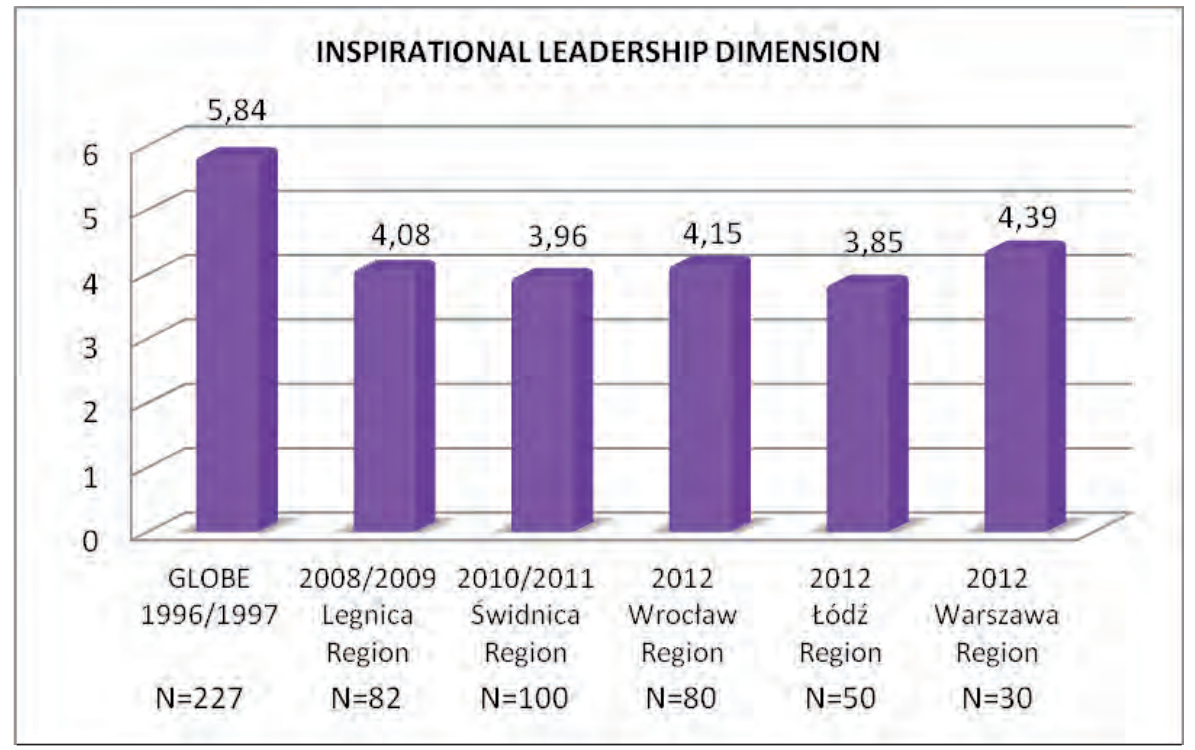

Results presented in Figure 7, indicate that Polish middle managers studied under our follow-up study display significantly lower level of Inspirational Leadership attribute than their counterparts investigated in the years of 1996/1997 under the GLOBE research project.

Based on the GLOBE research results it can be concluded that an Inspirational Leadership behavior is concerned with an attempt to develop enthusiasm and commitment by arousing strong emotions pertaining to followers needs, values, dreams and ideas. Inspirational leadership behavior may appeal to followers desire to be important, to feel useful and take advantage of their skills, to accomplish worthwhile organizational objectives, to perform an exceptional task, to be a member of outstanding team, or to participate in an fascinating and inspiring effort to perform tasks better.

To be able to articulate suitable inspirational appeals, the leader should have insight into the values, expectations, and fears of the followers or team to be influenced. The effectiveness of an inspirational leadership behavior also depends on the leader's communication skills, such as the ability to use creative ideas, and employ suitable voice and gestures to generate enthusiasm, excitement and motivation [Yukl, 1998].

\section{Conclusion}

In summary, our overall purpose in this paper was to compare followers evaluation of Polish middle managers in respect to their leadership attributes, 
in the years of 2008/2009, 2010/2011, 2012 and during 1996/1997 within the GLOBE research project.

Our findings with respect to attributes associated with leadership effectiveness are largely consistent, in our follow-up study, across the years of investigation and regions of Poland under the study. At the same time data collected in our follow-up study differ significantly with the results received under the GLOBE investigation.

It was surprising and to some extent unexpected that new generation of Polish middle managers investigated in the years of 2008/2009, 2010/2011 and 2012, among other aspects, disclosed substantially less negative attitude towards autocratic leadership attribute than did their counterparts investigated under the GLOBE project in 1996/1997.

Based upon our research data, it could be concluded that the more autocratic leadership style is applied towards followers, there is less opportunity to manifest humane orientation, team orientation, integrity, visionary and inspirational leadership attributes in organizational practices.

It has been internationally accepted that managerial leadership style is influenced by the concept of national culture which is labeled "Power Distance". Based on a survey of 116000 employees in 40 countries, Hofstede defines this construct as "the extent to which a society accepts the fact that power in institutions and organizations is distributed equally [1980, p.45].

High power distance is dysfunctional since it discourage members of the society or organization from debate and voicing of divergent views. Asking questions may be regarded as criticizing and blaming, and therefore may not be allowed. In contrast within the low power distance societies, the flexible distribution of power is expected to reinforce entrepreneurial innovation, broader participation in decision making, and to restrain the abuse of power and corruption.

Relatively high levels of power distance in Poland are also in line with results of studies conducted by Sułkowski [2008; 2009], who suggests that through the use of empowerment techniques one could awaken initiative and responsibility for one's own life. According to Sułkowski "Evolutionary research may be used to interpret sources of behaviors connected with power and to show possibilities of limiting some dangers" [2009, p.67].

Within the GLOBE research, we found that societies who score lower on Power Distance practices and values tend to be more economically prosperous and competitively successful, enjoy higher levels of societal health, and human development [House, et al., 2004, p.556].

We have assumed that the current circumstances in Poland are vastly different from the situation that prevailed at the time when our original 


\section{J. Mączyński, Ł. Sułkowski, M.Chmielecki, A. Zajączkowska}

data were collected in 1996/97 under the GLOBE project. That's why we have speculated that profound changes in social, economic and organizational arrangements in Poland should diminish Power Distance in organizational practices, and lead to more negative attitude towards autocratic managerial behaviors from the part of newer generation of Polish managers.

Our research results clearly show a resistance to immense political and socioeconomic change. Organizational practices in Polish organizations remain relatively autocratic. Interpreting our findings in this light leads to the conclusion that profound changes in political and socioeconomic systems are not sufficient factors that would have the power to modify organizational values and subsequent practices and behaviors. It would mean that deep changes in the mentality of people are needed to generate beneficial changes in the cultural values and succeeding attitudes and behaviors [Hofstede, 1980; 1991; 2000; Martan, 1993; Mączyński, et al., 2010].

It should be emphasized, that progressing autocratic managerial practices may produce unfortable situation for Polish organizations, and would become dysfunctional for organizational survival and development. This leads to the conclusion that in order to cope successfully with the current worldwide economic crisis, Polish managers would have to acquire such values and managerial behaviors, which would favor, among other aspects, application and development of human capital and potentials of their followers.

We hope that potential benefits resulted from our research on leadership traits and behaviors may have significant implications for improving managerial performance. Conclusions drawn from our findings might be helpful, among other aspects, in selection and placement of candidates for managerial positions and formal management training programs.

\section{Bibliography}

Hofstede, G. (1980). Culture's consequences: International differences in work-related values. CA: Sage, Beverly Hills.

Hofstede, G. (1991). Cultures and organizations: Software of the mind. London: McGrawHill.

Hofstede, G. (2000). Kultury i organizacje. Zaprogramowanie umysłu. Warszawa: Polskie Wydawnictwo Ekonomiczne.

Hofstede, G., and Bond, M.H. (1988). The Confucius connection: From cultural roots to economic growth. Organizational Dynamics, 16(4), pp. 4-21.

House, R.J., Hanges, P.I., \& Ruiz-Quintanilla, S.A. (1997). GLOBE: The global leadership and organizational behavior effectiveness research program. Polish Psychological Bulletin, 28, pp. 215-254.

House, R.J., Hanges, P.J., \& Ruiz-Quintanilla, S.A., Dorfman, P.W., Javidan, M.,Dickson, 
M.W., Gupta, V., \& 159 co-authors (1999). Cultural influences on leadership and organizations: Project GLOBE. [in:] W. Mobley, J. Gessner, \& V. Arnold (eds.), Advances in global leadership., JAI Press, Stamford, pp. 171-233.

House R.J., Wright, N.S., \& Aditya, R.N. (1997). Cross-cultural research on organizational leadership: A critical analysis and proposed theory. [in:] P.C. Early \& M. Erez (eds.), New perspectives in international organizational psychology. San Francisco, pp.535-625. New Lexington.

House, R.J., et al. (2004). Culture, leadership, and organizations. The GLOBE study of 62 societies. Sage Publications, Thousand Oaks, London, New Delhi.

Mączyński, J. (1998). Diagnosing decision participation. Warsaw: Polish Academy of Sciences Press.

Mączyński, J. (2001). The cultural impact on the leadership style of Polish managers. [in:] Polish Journal of Applied Psychology, vol. 1(1), pp. 107-132.

Mączyński, J. (2002). Cultural determinants of leadership style of Polish managers. [in:] G. Reber (eds.) Management in einer Welt der Globalisierung und Diverität. SchäfferPoeschel Verlag, Stuttgart, pp. 195-216.

Mączyński, J., Jago, A.G., Reber, G. \& Böhnisch, W. (1994). Culture and leadership styles: A comparison of Polish, Austrian and US managers. Polish Psychological Bulletin, 25, pp. 305-315.

Mączyński, J., Łobodziński, A., Wyspiański, D., Kwiatkowski, P. (2010). Differences on organizational practices and preferred leader attributes between Polish managers investigated in 1996/1997 and 2008/2009. Polish Psychological Bulletin, vol. 41, pp. 127-132.

Martan, L. (1993). The necessary change of human mentality. Organization and Management, 73, pp. 89-95.

Mc Clleland, D.C. (1987). Human motivation. Cambridge, UK: Cambridge University Press.

Peters, T.J., and Austin, N. (1985). A passion for excellence: The leadership difference. New York: Random House.

Sułkowski, Ł. (2008). Empowerment methods in social projects managements. Intercultural Management Studies, pp. 241-246.

Sułkowski, Ł. (2009). Universal sources of hierarchy and power from the perspective of neoevolutionism. Journal of Intercultural Management, vol. 1, No. 2, pp. 59-69.

Szabo, et al. (1997). Autocratic polish versus participative Austrian leaders: More than a cliché? Polish Psychological Bulletin, vol. 28, No. 3, pp. 279-291.

Thomas, M.A., Greenberger, D.B. (1985). The relationship between leadership and time orientation. Journal of Management Inquiry, 4, pp. 272-292.

Tichy, N.M., and Devanna, M.A. (1986). The transformational leader. New York: John Wiley.

Yukl, G. (1994). Leadership in organizations. Upper Saddle River, NJ: Prentice Hall. 